\title{
SIMPLIFIED MATHEMATICAL MODEL OF GROUP OF OVERHEAD POWER LINES MAGNETIC FIELD
}

Aim. The method for design of simplified mathematical model of the group of overhead power lines magnetic field allowing to reduce the number of conductors which are taken into account in the model and field and allowing to reduce the sensitivity of the model to plant parameters uncertainty is developed. Methodology. The method based on the multi-criteria game decision, in which the payoff vector is calculated on the basis of the Maxwell equations quasi-stationary approximation solutions. The game decision based on the stochastic particles multiswarm optimization algorithms. The implementation of the method is carried out when determining the number, configuration, spatial arrangement and currents in conductors based on simplified mathematical model of the group of overhead power line magnetic field in a given space area. Results. Computer simulation and field experimental research results of simplified mathematical model on the example of the group of four overhead power lines magnetic field including 21 conductors where based on the developed simplified mathematical model of the magnetic field, the number of conductors taken into account in the model is reduced to 6, and the modeling error does not exceed $4 \%$. Originality. For the first time the method for design of simplified mathematical model of the group of overhead power lines magnetic field based on the stochastic particles multiswarm optimization algorithms, which allows to significantly simplify the simulation by reducing the number of conductors that are taken into account in the model and to reduce the sensitivity of the model to plant parameters uncertainty, and at the same time limit the modeling error at the engineering level to 5-10\%. Practical value. Practical recommendations on reasonable choice of the minimal number, configuration, spatial arrangement and currents in conductors for the simplified mathematical model of the group of overhead power line magnetic field. References 32, figures 6. Key words: overhead power lines, magnetic field, simplified mathematical model, computer simulation, field experimental research.

Цель. Разработан метод построения упрощенной математической модели магнитного поля группы воздушных линий электропередачи, позволяющий уменьщить количество проводников, которые учитываются в модели для снижения чувствительности модели к неопределенности параметров объекта управления. Методология. Метод основан на решении многокритериальной стохастической игры, в которой векторный выцгрыш вычисляется на основании решений уравнений Максвелла в квазистационарном приближении. Решение игры находится на основе алгоритмов стохастической мультиагентной оптимизации мультироем частиц. Реализация метода осуществляется при определении количества, конфигурации, пространственного расположения и токов в проводниках на основе упрощенной математической модели магнитного поля группы воздушных линий электропередачи в заданной области пространства. Результаты. Приводятся результаты компьютерного моделирования и полевых экспериментальных исследований на примере группы из четырех воздушных линий электропередачи, содержащей 21проводник, где на основе разработанной упрощенной математической модели магнитного поля количество учитываемых в модели проводников уменьшено до 6, а погрешность моделирования при этом не превышает 4 \%. Оригинальность. Впервые разработан метод построения упрощенной математической модели магнитного поля группы воздушных линий электропередачи на основе алгоритмов стохастической мультиагентной оптимизации мультироем частиц, позволяющий существенно упростить моделирование за счет уменьщения количества проводников, которые учитываются в модели для снижения чувствительности модели к неопределенности параметров объекта управления, и при этом ограничить погрешность моделирования на инженерном уровне 5-10 \%. Практическая ценность. Приводятся практические рекомендации по обоснованному выбору минимального количества, конфигурации, пространственного расположения и токов в проводниках упрощенной математической модели магнитного поля, создаваемого группой воздушных линий электропередачи. Библ. 32, рис. 6.

Ключевые слова: воздушная линия электропередачи, магнитное поле, упрощенная математическая модель, компьютерное моделирование, полевые экспериментальные исследования.

Introduction. The World Health Organization stated that exposure to extremely low frequency magnetic field (MF) at power frequencies $50-60 \mathrm{~Hz}$ could lead to an increased incidence of cancer. This leads to modern world trends on stricter sanitary standards for the power frequency MF. In particular, in Ukraine the reference level is $0.5 \mu \mathrm{T}$ for living space [1]. Many of overhead power lines (OPL) often pass in the residential areas and generated a MF, the level of which often exceeds Ukraine sanitary standards, that poses a threat to public health $[2,3]$

Ukraine's electricity networks are characterized by high density, and especially near high-voltage power substations. There is usually a group of overhead OPL, in the immediate vicinity of which can be located residential buildings. As an example in Fig. 1 is shown a photograph of the location of 4 group of OPL including 21 conductors, generating MF, the magnetic flux density level of which must be reduced in the considered space.

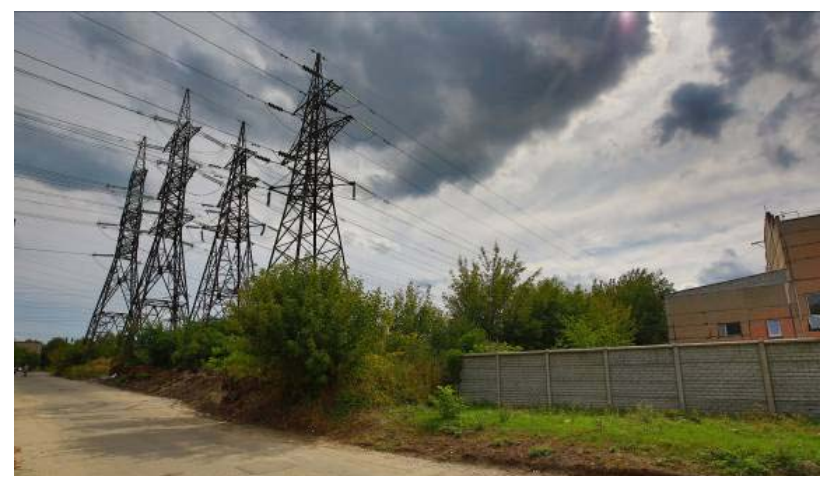

Fig. 1. Group of high voltage power lines

Active contour shielding methods are most economical for securing sanitary standards [3]. The systems of active shielding (SAS) synthesis method

(C) B.I. Kuznetsov, T.B. Nikitina, I.V. BovduI 
developed in [4-9]. In SAS usually use simultaneous open loop and closed loop control - two degree of freedom system [10-14].

The initial data for the synthesis of the SAS are the parameters of the transmission lines (working currents, geometry and number of wires, location of the transmission lines relative to the protected space) and the dimensions of the shielding space and magnetic flux density sanitary standards level, which should be achieved as a result of shielding [15-22].

The complexity of the synthesis problem solving of SAS is determined by the number of OPL conductors. Naturally, taking into account all OPL conductors that generated $\mathrm{MF}$ in the shielding zone, the task of synthesizing the SAE is complicated.

Therefore, it is relevant the approach to synthesis of SAS, which makes it possible to simplify the solution to the synthesis problem by taking into account a smaller number of wires in comparison with the original problem.

In this approach, the problem of approximating of the initial MF measured as a result of experimental studies with the help of several wires is solved. Depending on the required accuracy of approximation, the number of wires taken into account can be reduced to six, three or even two wires, which can significantly simplify the solution to the problem of synthesis of SAS.

The SAS plant parameters are known uncertainty [22-28]. In this case, the main uncertainty in the synthesis of this SAS is the variation of the bus currents in different OPL, which leads not only to a change in the magnetic flux density level, but also to a change in the position of the space-time characteristics (STC) of the MF in the shielding space due to the relative redistribution of the vertical and horizontal components of the magnetic flux density vector generated by various power lines. Therefore, the such simplified mathematical model of the initial magnetic field must be robust [22-28].

The goal of this paper is to develop the method for designing of mathematical model of the group of overhead power lines magnetic field, which allows to significantly simplify the simulation and at the same time limit the modeling error at the engineering level of 5-10\%.

Problem statement. Let us first consider the initial mathematical model of a magnetic field generated by group of OPL. In the future, we will call this model accurate. Consider the group of OPL consisting of $K$ OPL. Each $K$ OPL consists from $L_{k}$ wires. At first, we conduct experimental research of the magnetic flux density level both in the shielding space and near the power transmission line. Based on the obtained data, we solve the problem of identifying currents in initial OPL wires, at which the sum of the squared errors of the measured and model values of the magnetic flux density at given points is minimized.

Based on the calculated current wires levels we set the instantaneous current value $I_{l k}(t)$ at time $t$ in $l_{k}$ wire in $k$ OPL in the following form

$$
I_{l k}(t)=A_{l k} \sin \left(\omega t+\varphi_{l k}\right) \text {. }
$$

Consider the $l_{k}$ wire of any rather complex configuration with an instantaneous current value $I_{l k}(t)$ at time $t$ in the form of $n$ vector elementary segments $\Delta \boldsymbol{L}_{i}$ of sufficiently short length. Then the total magnetic flux density vector $\boldsymbol{B}_{l k}\left(Q_{i}, I_{l k}(t)\right)$ at the considered point $Q_{i}$, generated by $n$ elementary segments of a $l_{k}$ wire with an instantaneous current value $I_{l k}(t)$ can be determined $[2,3]$ on the basis of a quasistationary solution of the Maxwell equation in the following form

$$
\boldsymbol{B}_{k l}\left(Q_{j}, I_{l k}(t)\right)=\frac{\mu_{0} I_{l k}(t)}{4 \pi} \sum_{i=1}^{n} \frac{\Delta \boldsymbol{L}_{i} \times \boldsymbol{R}_{i}}{\left|R_{i}\right|^{3}},
$$

where $\mu_{0}$ is the vacuum permeability, $\Delta \boldsymbol{L}_{i x}-$ vector differential element at the direction of current; $\boldsymbol{R}_{i}$ - vector whose magnitude $\left|R_{i}\right|$ is the distance from the source to the observation point $Q_{i}$.

Then the total magnetic flux density vector $\boldsymbol{B}\left(Q_{i}, \boldsymbol{I}(t)\right)$ at the point $Q_{i}$, generated by all $L_{k}$ wires by all $K$ OPL can be represented as follows

$$
\boldsymbol{B}\left(Q_{j}, I(t)\right)=\sum_{k=1}^{K} \sum_{l=1}^{L_{k}} \boldsymbol{B}_{k l}\left(Q_{j}, I_{l k}(t)\right),
$$

where the vector of instantaneous currents $I(t)$ at time $t$ of all $L_{k}$ wires of all $K$ OPL is introduced, whose components are instantaneous current value $I_{l k}(t)$ at time $t$ of $l_{k}$ wire.

We introduce the vector $\boldsymbol{X}$ of the required parameters, the components of which are the number, configuration, spatial arrangement and currents in conductors of overhead power lines for the simplified mathematical model of the initial magnetic field.

Then for simplified mathematical model the total magnetic flux density vector $\boldsymbol{B}_{M}\left(Q_{i}, I_{M l k}(t)\right)$ at the same point $Q_{i}$, generated by all $L_{M k}$ wires of model can be represented as follows

$$
\begin{aligned}
& \boldsymbol{B}_{M}\left(Q_{j}, \boldsymbol{X}, \boldsymbol{I}_{M}(t)\right)=\sum_{k=1}^{K} \sum_{l=1}^{L_{k}} \boldsymbol{B}_{M k l}\left(Q_{j}, \boldsymbol{X}, \ldots\right. \\
& \left.\ldots, \boldsymbol{I}_{M l k}(t)\right),
\end{aligned}
$$

in which the total magnetic flux density vector $\boldsymbol{B}_{M l k}\left(Q_{i}, I_{M l k}(t)\right)$ at the considered point $Q_{i}$, generated by $\mathrm{n}$ elementary segments of a $l_{M k}$ wire of model with an instantaneous current value $I_{M l k}(t)$ can be determined [13] on the basis of a quasistationary solution of the Maxwell equation coherently (1).

The vector of instantaneous model currents $\boldsymbol{I}_{M}(t)$ at time $t$ of all $L_{M k}$ wires of model is introduced, whose components are instantaneous current value $I_{M l k}(t)$ at time $t$ of $l_{k}$ wire.

Consider the magnetic flux density vector $\boldsymbol{E}\left(Q_{i}, \boldsymbol{X}, I_{M}(t), I(t)\right)$ of error between the initial magnetic flux density vector $\boldsymbol{B}\left(Q_{i}, I(t)\right)$ and magnetic flux density vector $\boldsymbol{B}_{M}\left(Q_{i}, I_{M}(t)\right)$ of approximate mathematical model at the considered points $Q_{j}$ at time $t$

$$
\begin{aligned}
& \boldsymbol{E}\left(Q_{j}, \boldsymbol{X}, \boldsymbol{I}_{M}(t), \boldsymbol{I}(t)\right)=\boldsymbol{B}\left(Q_{j}, \boldsymbol{I}(t)\right)-\ldots \\
& \ldots-\boldsymbol{B}_{M}\left(Q_{j}, \boldsymbol{X}, \boldsymbol{I}_{M}(t)\right) .
\end{aligned}
$$

To estimate the simplified mathematical model error we calculate the effective value $E\left(Q_{i}, \boldsymbol{X}\right)$ of the error vector $\boldsymbol{E}\left(Q_{i}, \boldsymbol{X}, \boldsymbol{I}_{M}(t), I(t)\right)$ by numerically integrating the squared modulus of the error vector over the time interval $T=20 \mathrm{~ms}$ of the period of the magnetic flux density vector change 


$$
E\left(Q_{i}, \boldsymbol{X}\right)=\frac{\sqrt{2}}{2} \sqrt{\frac{1}{T} \int_{0}^{T}\left|\boldsymbol{E}\left(Q_{i}, \boldsymbol{X}, \boldsymbol{I}_{M}(t), \boldsymbol{I}(t), t\right)\right|^{2} d t .}
$$

Method or designing. In the designing of the simplified mathematical model (3), the mathematical model of the original MF (2) is known inaccurately $[19,20]$. In particular, currents in current conductors that have daily, weekly, seasonal variations are approximately known. Therefore, we introduce a vector $\delta$ of the uncertainty parameters from their nominal values used in the design of the approximate mathematical model. Then the problem of design of the robust approximate the mathematical model is reduced to the determination of such a vector $\boldsymbol{X}$ of the required parameters, the components of which are the number, configuration, spatial arrangement and currents in conductors of overhead power lines for the approximate robust mathematical model of the initial magnetic field and the vector of uncertainty parameters $\delta$, at which the maximum value of the magnetic field induction at selected points $P_{i}$ of the considered space $P$ assumes a minimum value for the required parameter vector $\boldsymbol{X}$, but the maximum value for the vector of uncertainty parameters $\delta$ so that

$$
\boldsymbol{X}^{*}=\arg \min _{\boldsymbol{X} \in \boldsymbol{X}} \max _{\boldsymbol{\delta} \in \boldsymbol{\Delta}} \max _{\boldsymbol{Q}_{i} \in \boldsymbol{Q}} E\left(\boldsymbol{X}, \boldsymbol{\delta}, Q_{i}\right) .
$$

This technique corresponds to the standard approach to the design of robust systems for the worst-case [29], when the uncertainty parameters $\delta$ lead to the greatest deterioration of the approximated model accuracy.

The problem (7) can formulated in the form of the following multi objective game [30-32] with vector payoff

$$
\begin{aligned}
& \boldsymbol{E}(\boldsymbol{X}, \boldsymbol{\delta})=\left[E\left(\boldsymbol{X}, \boldsymbol{\delta}, Q_{1}\right), E\left(\boldsymbol{X}, \boldsymbol{\delta}, Q_{2}\right) \ldots\right. \\
& \left.. . E\left(\boldsymbol{X}, \boldsymbol{\delta}, Q_{m}\right)\right]^{T},
\end{aligned}
$$

the components of which $E\left(\boldsymbol{X}, \delta, Q_{i}\right)$ are the error between the initial magnetic flux density and magnetic flux density of approximate mathematical model in the $m$ points $Q_{i}$ of the space under consideration.

In the multi-objective game (8), the first player is the parameter vector of the approximate mathematical model $\boldsymbol{X}$ and its strategy is the minimization of the vector payoff and the second player is a vector $\delta$ of uncertainty parameters and the strategy of this player is maximization of the same vector payoff [32].

Note that the components of the vector payoff (2) are nonlinear functions of the required parameters vectors $\boldsymbol{X}$ and $\boldsymbol{\delta}$ are calculated on the basis of the Maxwell equations solutions in the quasi-stationary approximation $[2,3]$.

To find the multi-criterion games decision from Pareto-optimal decisions [30] taking into account the preference relations [31], we used special nonlinear algorithms of stochastic multi-agent optimization [32].

Computer simulation results. Consider the results of designing of the simplified mathematical model of a magnetic field generated by group of OPL including 21 conductors. In Fig. 2 are shown layout of group OPL and shielding space. The initial MF in the shielding space generated by two double-circuit $110 \mathrm{kV}$ OPL (OPL-1 and
OPL-2), a two-circuit $330 \mathrm{kV}$ OPL (OPL-3) and a singlecircuit $330 \mathrm{kV}$ OPL (OPL-4).

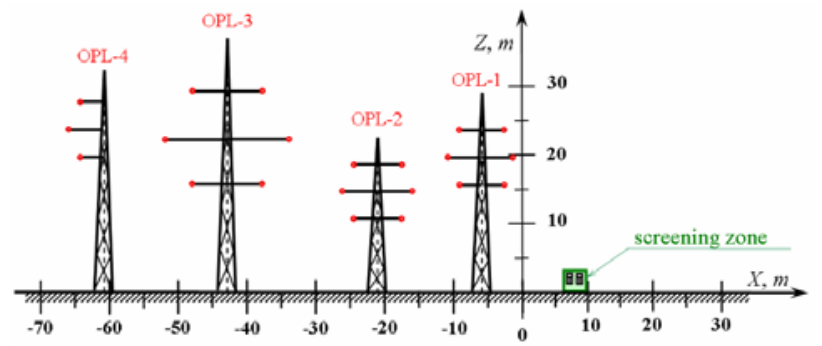

Fig. 2. Layout of group OPL and shielding space

In Figure 3 are shown the isolines of magnetic flux density, calculated for the nominal currents of group of OPL.

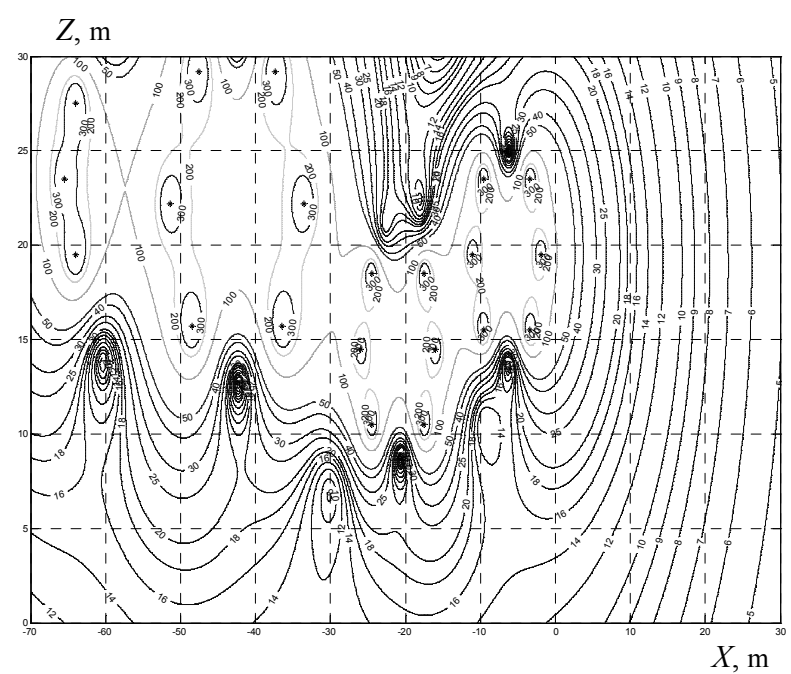

Fig. 3. The isolines of magnetic flux density, calculated for the nominal currents of group of OPL

Modeling of the magnetic flux density created by individual OPL in the shielding space carried out. The currents in the wires of all OPL were assumed to be the same and equal to $500 \mathrm{~A}$. In Fig. 4 are shown the results of calculations of the distribution of the magnetic flux density in the shielding space during operation: $a$ ) only one OPL-4; $b$ ) during the operation of two OPL-3 and OPL-4; c) during operation of three OPL-2, OPL-3 and OPL-4; and $d$ ) during operation of four OPL-1, OPL-2, OPL-3 and OPL-4.

Based on the analysis of the dependencies are shown in Figure 4 shows that as the OPL is removed from the shielding space, the magnetic flux density level of generated by this OPL in the shielding space decreases.

However, in the case under consideration, the nominal currents in the OPL-3 and OPL- 4 are $2000 \mathrm{~A}$, but the nominal currents in OPL-1 and OPL-2 are $1000 \mathrm{~A}$. Therefore, despite the fact that OPL-3 and OPL-4 are removed from the shielding space at a greater distance than OPL-1 and OPL-2, the influence of OPL-4 and, especially, OPL-3 on the magnetic flux density level in the shielding space can be significant.

Depending on the required accuracy of approximation robust mathematical model the number of power transmission wires taken into account can be reduced to six, three or even two wires. By dint of 
approximation robust mathematical model in which only two current wires are taken into account, it is possible to simulate only weakly polarized field, in which the spacetime characteristic is a strongly elongated ellipse. If the space-time characteristic of the initial magnetic field is close to a circle, then the minimum number of wires is two.

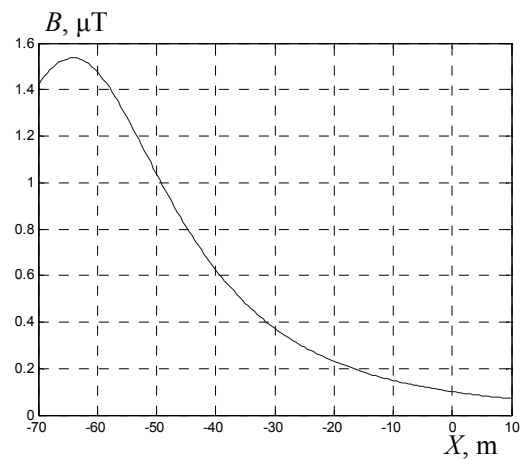

$a$

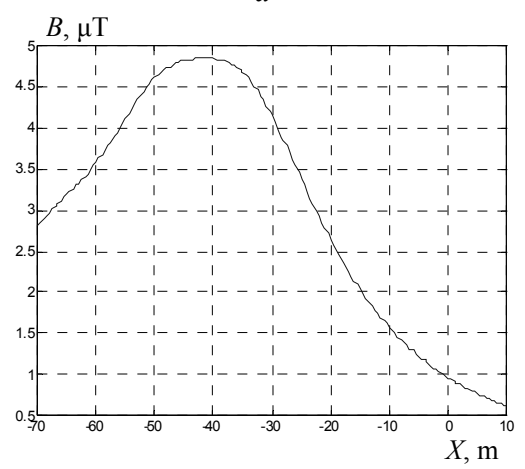

$b$

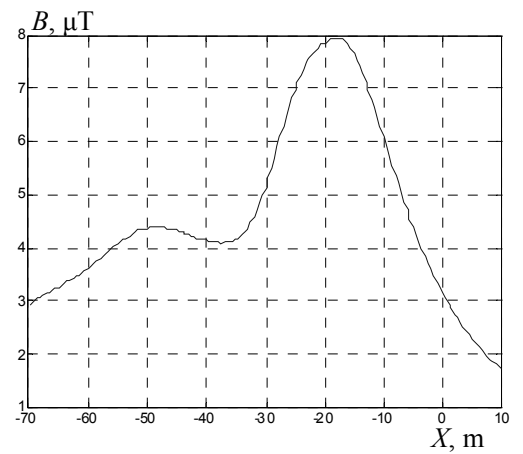

$c$

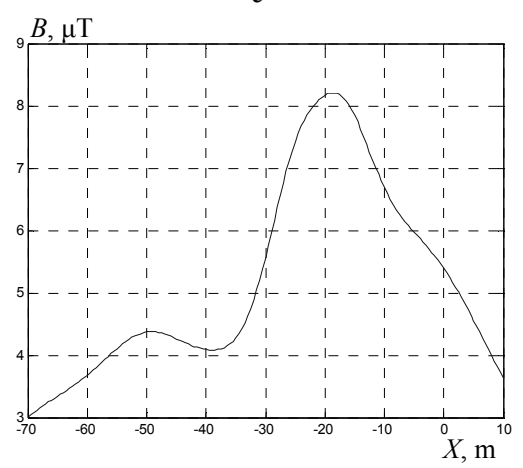

$d$

Fig. 4. The magnetic flux density distribution in the shielding space during operation: a) only one OPL-4;

b) both OPL-3 and OPL-4;

c) OPL-2, OPL-3 and OPL-4;

d) all OPL-1, OPL-2, OPL-3 and OPL-4
Experimental research. Experimental research of the magnetic field generated by these group of OPL in the shielding space, in which it is necessary to reduce the MF level to sanitary standards, are shown that the values of magnetic flux density calculated at the nominal values of power line currents and measured values are very different.

Therefore, initially, based on experimental research of magnetic flux density generated by currents in 21 conductors of the 4 group of OPL were determined. For these currents, the original accurate model of MF (2) is constructed. The approximated model (3) was designing for this accurate model. The simplified model include 6 conductors.

In Fig. 5 are shown the isolines of magnetic flux density of simplified model of the magnetic field generated by group of OPL.

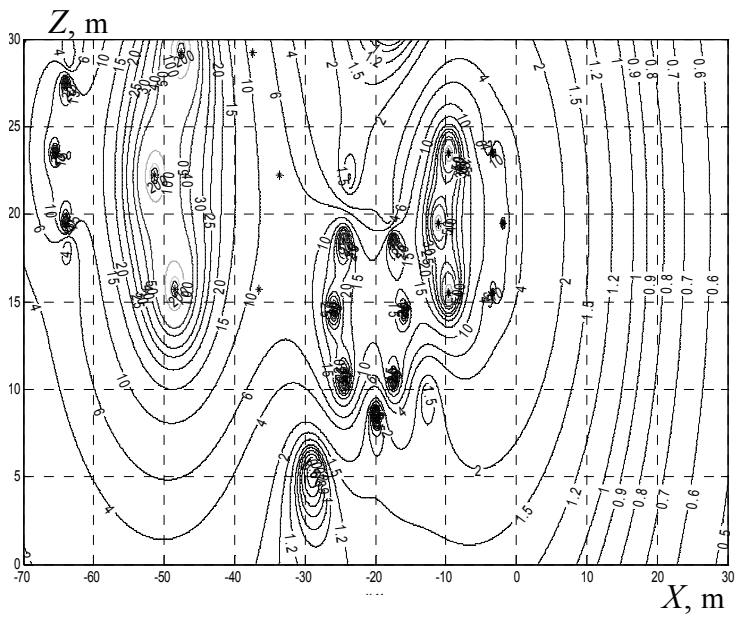

Fig. 5. The isolines of magnetic flux density of approximated model of the magnetic field generated by group of power lines

In Figure 6 are shown the dependences of the magnetic flux density of 1) simplified model and 2) measured values. A comparison of the results of modeling and experimental research of the distribution of magnetic flux density values in the shielding space showed that the error between such an simplified model and experimental measured values of the magnetic flux density level does not exceed $4 \%$.

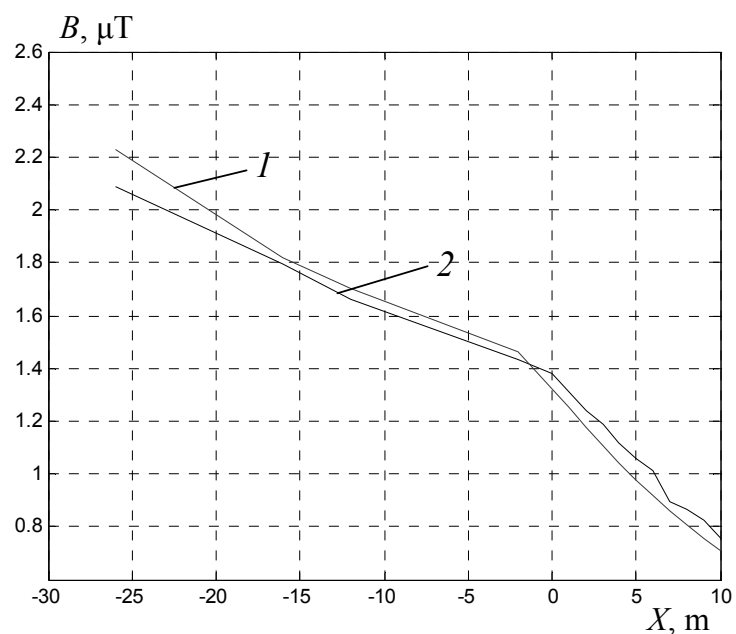

Fig. 6. The dependences of the magnetic flux density of 1 - approximated model and $2-$ measured values 
In addition, this simplified model use for the synthesis of SAS. Results of comparison of modeling and experimental research confirms the possibility of active shielding of the initial MF in the shielding space with the shielding factor more than 4 .

In conclusion, we note that designing of simplified mathematical model of the initial magnetic field is equivalent to synthesis of system of active shielding of magnetic field. When designing of simplified mathematical model, it is necessary to determine the number, configuration, spatial arrangement and currents in conductors of overhead power lines for the simplified mathematical model of the initial magnetic field. This is the vector game solution.

When synthesis of system of active shielding of magnetic field, it is also necessary to determine the number, configuration, spatial arrangement and shielding coils currents, and the control systems parameters. This is also the vector game solution.

The components of the game vector payoff in the design of the approximate mathematical model are errors between the magnetic flux density level of the initial and approximated moles. And the components of the game vector payoff in the design of the of system of active shielding of magnetic field are the errors of screening of the initial magnetic field by the screening coils of the system of active shielding of magnetic field.

Therefore, when calculating the components of the game vector gain for designing of simplified mathematical model, it is enough to change the sign in the expression for to calculate the components of the game vector payoff in the design of the system of active shielding of magnetic field.

Therefore, from the point of view of the mathematical statement of the problems of designing of simplified mathematical model and synthesis of robust system of active shielding of magnetic field are tasks of approximating of the initial magnetic field. However, when designing of the simplified mathematical model, the wires are located in the zone of the power transmission line, but when designing the system of active shielding of magnetic field, the shielding coils are located near the shielding space.

Conclusions.

1. For the first time the method of design of simplified mathematical model of the group of overhead power lines magnetic field which can significantly simplify the simulation and at the same time limit the modeling error at the engineering level of 5-10\% is develop. The method based on reducing the number of conductors that are taken into account in the model and on reducing the sensitivity of the model to plant parameters uncertainty. Depending on the required accuracy of simplified mathematical model the number of power transmission wires taken into account can be reduced to six, four, three or even two.

2. The design of simplified mathematical model based on multi-criteria stochastic game decision, which is calculated by multiswarm stochastic multi-agent optimization from Pareto-optimal solutions. Multi-criteria game vector payoff is calculated based on the Maxwell equations solution. The number, configuration, spatial arrangement and currents in conductors of overhead power lines for the simplified mathematical model and resulting magnetic flux density value in the shielding space are determined by the simplified model designing.

3 . The results of computer modeling and field experimental studies on an example of a group of four overhead power lines containing 21 conductors confirm the correctness of the developed simplified mathematical model and the possibility of reducing the number of conductors taken into account in the model to 6 while limiting the modeling error to level of $4 \%$.

4. It shown, that it is equivalent from the point of view of the mathematical statement the problems of designing of simplified mathematical model and synthesis of system of active shielding of magnetic field are tasks of approximating of the initial magnetic field.

\section{REFERENCES}

1. Pravila ulashtuvannya electroustanovok [Electrical installation regulations]. Kharkiv, Fort Publ., 2017. 760 p. (Ukr).

2. Rozov V., Grinchenko V. Simulation and analysis of power frequency electromagnetic field in buildings closed to overhead lines. 2017 IEEE First Ukraine Conference on Electrical and Computer Engineering (UKRCON). Kyiv, Ukraine, pp. 500-503. doi: 10.1109/UKRCON.2017.8100538.

3. Rozov V.Yu., Grinchenko V.S., Yerisov A.V., Dobrodeyev P.N. Efficient shielding of three-phase cable line magnetic field by passive loop under limited thermal effect on power cables. Electrical engineering \& electromechanics, 2019, no.6, pp. 5054. doi: 10.20998/2074-272X.2019.6.07.

4. Active Magnetic Shielding (Field Cancellation). Available at: http://www.emfservices.com/afcs.html (accessed 10 September 2012).

5. Rozov V.Yu., Reutskyi S.Yu., Pelevin D.Ye., Pyliugina $\mathrm{O} . Y u$. The magnetic field of transmission lines and the methods of its mitigation to a safe level. Technical Electrodynamics, 2013, no. 2, pp. 3-9. (Rus).

6. Rozov V.Yu., Reutskyi S.Yu. Pyliugina O.Yu. The method of calculation of the magnetic field of three-phase power lines. Technical electrodynamics, 2014, no.5, pp. 11-13. (Rus).

7. Salceanu A., Paulet M., Alistar B.D., Asiminicesei O. Upon the contribution of image currents on the magnetic fields generated by overhead power lines. 2019 International Conference on Electromechanical and Energy Systems (SIELMEN). 2019. doi: 10.1109/sielmen.2019.8905880.

8. Bravo-Rodríguez J., Del-Pino-López J., Cruz-Romero P. A Survey on Optimization Techniques Applied to Magnetic Field Mitigation in Power Systems. Energies, 2019, vol.12, no.7, p. 1332. doi: 10.3390/en12071332.

9. Canova A., Giaccone L., Cirimele V. Active and passive shield for aerial power lines. 25th International Conference on Electricity Distribution Madrid, 3-6 June 2019. Paper no. 1096, pp. 1-5.

10. Sushchenko O.A., Tunik A.A. Robust optimization of the inertially stabilized platforms. 2012 2nd International Conference «Methods and Systems of Navigation and Motion Control» (MSNMC), Kiev, 2012, pp. 101-105. doi: 10.1109/msnmc.2012.6475102.

11. Sushchenko O.A. Robust control of angular motion of platform with payload based on $\mathrm{H} \infty$-synthesis. Journal of Automation and Information Sciences, 2016, vol. 48, no. 12, pp. 13-26. doi: 10.1615/jautomatinfscien.v48.i12.20.

12. Sushchenko O.A. Robust control of platforms with instrumentation. 2019 IEEE 2nd Ukraine Conference on Electrical and Computer Engineering (UKRCON), Lviv, Ukraine, 2019, pp. 518-521. doi: 10.1109/ukrcon.2019.8879969. 
13. Zhiteckii L.S., Azarskov V.N., Solovchuk K.Y., Sushchenko O.A. Discrete-time robust steady-state control of nonlinear multivariable systems: a unified approach. IFAC Proceedings Volumes, 2014, vol. 47, no. 3, pp. 8140-8145. doi: 10.3182/20140824-6-za-1003.01985.

14. Zhiteckii L.S., Solovchuk K.Y. Robust adaptive pseudoinverse model-based control of an uncertain SIMO memoryless system with bounded disturbances. 2019 IEEE 2nd Ukraine Conference on Electrical and Computer Engineering (UKRCON), Lviv, Ukraine, 2019, pp. 621-627. doi: 10.1109/ukrcon.2019.8879824.

15. Chorna O., Chornyi O., Tytiuk V. Identification of changes in the parameters of induction motors during monitoring by measuring the induction of a magnetic field on the stator surface. 2019 IEEE International Conference on Modern Electrical and Energy Systems (MEES). Kremenchuk, 2019. doi: 10.1109/MEES.2019.8896554.

16. Chystiakov P., Chornyi O., Zhautikov B., Sivyakova G. Remote control of electromechanical systems based on computer simulators. 2017 International Conference on Modern Electrical and Energy Systems (MEES). Nov. 2017. doi: 10.1109/mees.2017.8248934.

17. Shenkman A., Sonkin N., Kamensky V. Active protection from electromagnetic field hazards of a high voltage power line. HAIT Journal of Science and Engineering. Series B: Applied Sciences and Engineering, Vol. 2, Issues 1-2, pp. 254-265.

18. Korol S., Buryan S., Pushkar M., Ostroverkhov M. Investigation the maximal values of flux and stator current of autonomous induction generator. 2017 IEEE First Ukraine Conference on Electrical and Computer Engineering (UKRCON), May 2017. doi: 10.1109/ukrcon.2017.8100302.

19. Ostroverkhov M., Buryk M. Control of permanent magnet synchronous motor under conditions of parametric uncertainty. 2019 IEEE International Conference on Modern Electrical and Energy Systems (MEES), Sep. 2019. doi: 10.1109/mees.2019.8896635.

20. Ostroverkhov M., Pyzhov V., Korol S. Control of the electric drive under conditions of parametric uncertainty and coordinates' interrelation. 2017 International Conference on Modern Electrical and Energy Systems (MEES), Nov 2017. doi: 10.1109/mees.2017.8248953.

21. Panchenko V.V., Maslii A.S., Pomazan D.P., Buriakovskyi S.G. Determination of pulsation factors of the system of suppression of interfering harmonics of a semiconductor converter. Electrical engineering \& electromechanics, 2018, no.4, pp. 24-28. doi: 10.20998/2074-272X.2018.4.04.

22. Buriakovskyi S.G., Maslii A.S., Panchenko V.V., Pomazan D.P., Denis I.V. The research of the operation modes of the diesel locomotive CHME3 on the imitation model. Electrical engineering \& electromechanics, 2018, no.2, pp. 59-62. doi: 10.20998/2074-272X.2018.2.10.

23. Buriakovskyi S., Maslii A., Maslii A. Determining parameters of electric drive of a sleeper-type turnout based on electromagnet and linear inductor electric motor. EasternEuropean Journal of Enterprise Technologies, 2016, vol.4, no.1(82), pp. 32-41. (Rus). doi: 10.15587/17294061.2016.75860.

How to cite this article:

Kuznetsov B.I., Nikitina T.B., Bovdui I.V. Simplified mathematical model of group of overhead power lines magnetic field. Electrical engineering \& electromechanics, 2020, no. 4, pp. 24-29. doi: 10.20998/2074-272X.2020.4.04.
24. Shchur I., Klymko V. Comparison of different types of electromechanical systems for creating of counter-rotating VAWT. 2017 IEEE First Ukraine Conf. on Electrical and Computer Engineering (UKRCON-2017), pp. 373-378. doi: 10.1109/ukrcon.2017.8100513.

25. Shchur I. Impact of nonsinusoidalness on efficiency of alternative electricity generation systems. 2010 International School on Nonsinusoidal Currents and Compensation, Lagow, 2010, pp. 218-223. doi: 10.1109/isncc.2010.5524483.

26. Zagirnyak M., Bisikalo O., Chorna O., Chornyi O. A model of the assessment of an induction motor condition and operation life, based on the measurement of the external magnetic field. 2018 IEEE 3rd International Conference on Intelligent Energy and Power Systems (IEPS). 2018. pp. 316-321. doi: 10.1109/ieps.2018.8559564.

27. Zagirnyak M., Chornyi O., Nykyforov V., Sakun O., Panchenko K. Experimental research of electromechanical and biological systems compatibility. Przeglad Elektrotechniczny, 2016, vol.1, no.1, pp. 130-133. doi: 10.15199/48.2016.01.31.

28. Zagirnyak M., Serhiienko S., Chornyi O. Innovative technologies in laboratory workshop for students of technical specialties. 2017 IEEE First Ukraine Conference on Electrical and Computer Engineering (UKRCON), May 2017. doi: 10.1109/ukrcon.2017.8100446.

29. Ren Z., Pham M.-T., Koh C.S. Robust Global Optimization of Electromagnetic Devices With Uncertain Design Parameters: Comparison of the Worst Case Optimization Methods and Multiobjective Optimization Approach Using Gradient Index. IEEE Transactions on Magnetics, 2013, vol.49, no.2, pp. 851859. doi: 10.1109/tmag.2012.2212713.

30. Galchenko V.Y., Yakimov A.N. A turmitobionic method for the solution of magnetic defectometry problems in structuralparametric optimization formulation. Russian Journal of Nondestructive Testing, 2014, vol.50, no.2, pp. 59-71. doi: 10.1134/s106183091402003x.

31. Gal'chenko V.Y., Yakimov A.N., Ostapushchenko D.L. Pareto-optimal parametric synthesis of axisymmetric magnetic systems with allowance for nonlinear properties of the ferromagnet. Technical Physics, 2012, vol.57, no.7, pp. 893899. doi: 10.1134/s1063784212070110.

32. Ummels M. Stochastic Multiplayer Games Theory and Algorithms. Amsterdam University Press, 2010. 174 p.

Received 25.05.2020

B.I. Kuznetsov ${ }^{1}$, Doctor of Technical Science, Professor,

T.B. Nikitina ${ }^{2}$, Doctor of Technical Science, Professor,

I.V. Bovdui ${ }^{1}$, Candidate of Technical Science,

${ }^{1}$ State Institution «Institute of Technical Problems

of Magnetism of the NAS of Ukraine»,

19, Industrialna Str., Kharkiv, 61106, Ukraine,

phone +380 505766900 ,

e-mail: kuznetsov.boris.i@gmail.com

${ }^{2}$ Kharkov National Automobile and Highway University,

25, Yaroslava Mudroho Str., Kharkov, 61002, Ukraine,

e-mail: tatjana55555@gmail.com 